\title{
Modeling and Simulation of Urban Traffic Signals
}

\author{
Khodakaram Salimifard and Mehdi Ansari
}

\begin{abstract}
Traffic signals play a vital role in effective traffic management. In this paper we apply Arena simulation tool box for modeling and simulation of urban traffic signal system. It has been shown that Arena could be used in simulation of traffic signals system, despite the fact that Arena is not designed for modeling urban traffic signal control. We presented a non-trivial case study to illustrate how Arena is capable of modeling traffic systems.
\end{abstract}

Index Terms-Urban traffic, traffic lights, discrete event simulation, Arena software.

\section{INTRODUCTION}

Transportation systems are essential to economic and the security of the nation [1]. The effectiveness of a transportation system depends on its ability to support the reliable movement of people, goods, and vehicles from one place to another. An urban traffic system is an important yet complex transportation system composed of vehicles, pedestrians, traffic lights, and a traffic network structure [2], [3]. Problems related to urban traffic is increasingly important, and many researchers are trying hard to solve them [2]. The huge number of vehicles causes serious problems like for example traffic jams, air and noise pollution, stress to drivers, and fuel and energy consumption [4].

The continuous form of traffic flow is principally modeled from a macroscopic point of view, which has been influenced from the hydrodynamic theory. In this matter, general variables such as flow rate, density, and average velocity describe the traffic flow. On the other hand, microscopic viewpoint that concentrates on the individual vehicles behaviors model the discrete form of traffic flow [5].

Urban traffic signal control is an important element of the safety for both pedestrians and vehicles when crossing an intersection or other paths [6]. The time between different flows is controlled by traffic signals which can be lead to the flow conflicts being resolved. This was the first reason for the invention of traffic signal in the early 1900s [7]. An urban traffic signal control system is a complex system characterized by randomness, burst, and uncertainty [8]. Utilizing a dependable model that can reflect the behavior of traffic control system is very important to realize traffic signal real-time control. Traffic control systems reduces as much as possible the delay by vehicles tripping by a network

Manuscript received January 30, 2013; revised April 1, 2013.

Khodakaram Salimifard is with the Department of Industrial Management, Persian Gulf University, Bushehr 75168 Iran (e-mail: salimifard@pgu.ac.ir).

Mehdi Ansari was with the Department of Industrial Management, Persian Gulf University, Bushehr 75168 Iran (e-mail: m20264ansari@yahoo.com). of intersections [9]. By utilizing a suitable control policy, a suitably designed urban traffic signal control can decrease problems like overcrowd, stop delay, air and noise pollution, fuel consumption, discomfort and stress [10].

Control policy of traffic control systems are grouped into two main categories. Fixed time strategies, which are implemented off-line using maximum efficiency codes based on important and historical traffic data. These strategies don't use information of real time traffic condition. Vehicle motivated strategies, which carry out an on-line synchronization and optimization of the signal scheduling programs. These strategies are traffic reactive signal control policy utilizing signal timing scheme that automatically answer to traffic requirement [8].

From a methodological viewpoint, because of different conflicting purposes, serious problems arise when controlling signalized intersections. Firstly, searching for the best fluidity is sometimes incompatible with the best safety. Controlling the traffic from a safety point of view implies constraints on the traffic signal color durations or correlations between traffic signals. These constraints imply limitations on traffic fluidity management. On the other hand, the users of traffic networks such as pedestrian, emergency vehicle, and bicycle often have concern crossing of an intersection [9]. These conflicting objectives require management choices, which will favor certain elements over others.

The remainder of the paper is organized as follows: a comprehensive literature review on the topic is summarized in Section II. Section III presents characteristics of queuing analysis of the system. Traffic simulation is described in Section IV. The proposed methodology of this paper consisting of a case study, simulation model, data collection and simulation results are presented in Section V. Finally, the paper is concluded in Section VI.

\section{LITERATURE REVIEW}

A comprehensive diversity of specifications such as exponential filtering, nonparametric statistical procedures, spectral and cross-spectral, and successive learning have been used by researchers [11] to model traffic attributes and present short-term predictions for the system. In addition, some researchers were interested in forecasting the urban traffic using a wide range of methods, such as ARIMA [12], generalized linear models, and neural networks [13]. Interestingly, Smith et al. [14] in a resemblance of historical norm, nonparametric regression, time series, and neural network models discover that the nonparametric regression model meaningfully exceed in performance comparing to the other models [15]. 
During the past decades, researchers have made immense attempt to develop signal matched control strategies for traffic network [12]. Baras et al. [16] used random-dot process theory to set up a mathematical model of an urban traffic control system. They suggested that performing delay-free control is troublesome because many factors need to be measured in the computation. New progress in intelligent control theory has caused the extensive utilization of artificial intelligent in urban traffic signal control [17].

Hierarchical control architecture of traffic systems investigated by Wei et al. [11]. Hong et al. [18] applied a class of fuzzy controls into the urban traffic signal control. Bingham [19] suggested a so called fuzzy-neuro method for urban traffic control. Fuzzy expert system and artificial neural networks were examined as a tool for control decisions in an urban traffic system [20]. An immediate signal control approach was created by Choy [21] to employ divided hybrid agents with online fuzzy support learning. Porche and Lafortune [22] introduced an immediate signal optimization plan for a large scale traffic system.

\section{A QUEUING VIEW OF THE SYSTEM}

An urban traffic system can be seen as a queuing system, in which roads, junctions, and traffic signals serve the flow of traffic. One can analyze a queuing system using three different classes of methods: analytical method, approximation, and simulation. An analytical method can be used for ordinary queuing systems with perfect characteristics. This is particularly the situation when concerned performances evaluations are only the inferior values. Analytical models are obedient only if one makes appropriate supposition. Anyway, when the problems turn into more complex or when the concerned performance measures contain distributions, the approximation method or simulation may be more appropriate [23]. Usually queuing system in nature can be supposed as discrete one. The system alters its stages on a happening foundation, such as the arrivals of vehicles and the finishing of service.

\section{A. Discrete Event Simulation}

A discrete event simulation model concentrates on the event times that can happen as these are the only times when the system is going to alters its mood. Examining the system in between the sequential event times is not essential for the simulator [24].

\section{B. Traffic Simulation}

Since its beginning, simulation has been applied to various sectors, such as manufacturing, services, defense, healthcare, and public services. Simulation is recognized as the second mainly used technical instrument in the field of operations management [25]. Traffic simulation has developed into a productive instrument to encounter the essential needs of transportation modeling and examination. Simulation has the capability in modeling the complex nature of an actual transportation system [26]. By creating a computer model and moving it through time, simulation is generally delineated as the dynamic and powerful representation of the process of the actual world performed [27].
Traffic simulation has proven to be a useful and cost effective approach for providing real time traffic information in support of incident discovery and incident analysis [28]. Traffic simulation systems and models are apportioned to various different classifications. One of the fundamental classifications is the division between macroscopic, microscopic and mesoscopic models [28].

Microscopic models [29] predict the mood of single and individual vehicles both continuous and discrete types like individual vehicle speeds and locations. But macroscopic models make ready an extensive depiction of the traffic flow situations while mesoscopic models include the mixed aspects of both microscopic and macroscopic models. Therefore, macroscopic models can only depict entities and their action or communication with low loyalty. Despite the mesoscopic model with combined loyalty represent entities at a proportionately high level as compared to the macroscopic one, it is quiet at a large amount lower level in depicting their actions and interactions as compared to microscopic model. Between the different kinds of aforementioned traffic simulation techniques, microscopic simulation techniques are the most suitable for simulating actual traffic conditions and examining control policies [28].

\section{METHODOLOGY}

\section{A. Case Study}

Bushehr is one of the main cities in the southern part of Iran. In this paper, discrete event simulation has been applied to provide a simulation model of an isolated traffic intersection. We concentrate on one of the main intersections of the urban traffic system of Bushehr. As depicted in Fig. 1, the traffic system consists of Emam, Bazargani, Bahonar and Helali streets. Emam Street is the main street of the traffic system. Cars crossing the intersection have the options to go straight or turn to either of the side roads. The intersection traffic light control uses a three phase policy consisting green, yellow, and red coding lights. If the light is green, a waiting vehicle can go straight or turn to left or right, depending only on the driver decision.

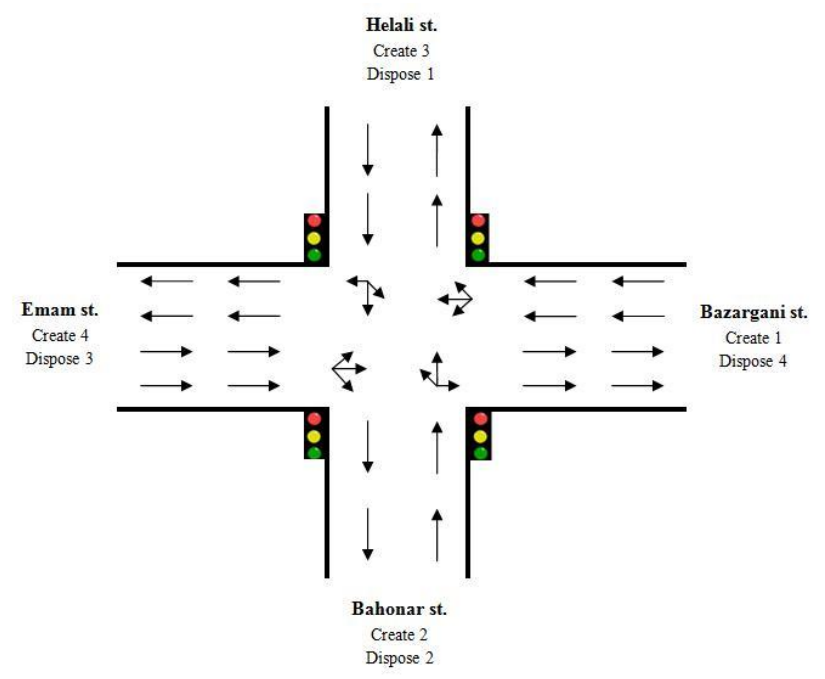

Fig. 1. Traffic flow of the intersection. 


\section{B. Simulation Model}

In this paper we have applied Arena 10 software [30] for modeling and simulation of the case study. Arena is a powerful interactive visual modeling and simulation tool and is principally employed for creating animated and dynamic models [31]. It is a very effective and applicable instrument for simulation of call centers, telecommunication queuing systems, and manufacturing material processes.

The model that is displayed in Fig. 2 is the basic model of the traffic system. This model is composed of 16 public modules called Create, Process, Decide and Dispose. We have used of 4 Create modules demonstrating the arrival of the vehicles to the center of intersection. Also, 4 Process modules demonstrate traffic lights, and 4 Decide modules represent branching probabilities of vehicles. The other 4 Dispose modules capture cars leaving the traffic system.

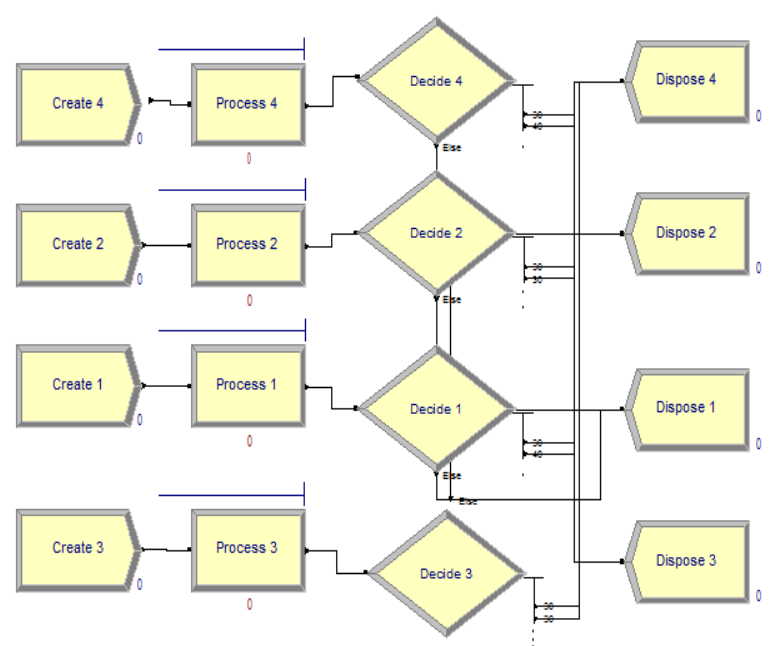

Fig. 2. Simulation model of the intersection.

\section{Simulation Results}

The following results are derived from simulation runs for a one week period.

1) Average waiting time of vehicles

Table I represents the waiting time (in hours) of cars in different queues. For example, incoming vehicles from Helali Street should wait for 13.9 seconds behind the traffic light. This time is 26 seconds for Emam Street.

TABLE I: WAITING TIME OF VEHICLES

\begin{tabular}{lllll}
\hline \hline Waiting time & Average & Half width & Min & Max \\
\hline Process 1 & 0.00002193 & 0.000000034 & 0.0 & 0.000688 \\
Process 2 & 0.00393959 & 0.000024898 & 0.0 & 0.0112497 \\
Process 3 & 0.00386486 & 0.000032327 & 0.0 & 0.01124707 \\
Process 4 & 0.00724130 & 0.000033388 & 0.0 & 0.02014854 \\
\hline \hline
\end{tabular}

\section{2) The lengths of vehicle queue}

We observed that in average, almost 12 (11.7456) vehicles. Table II represents the length of different queues of the intersection. It is easily comprehendible that the path from Emam Street toward Bazargani Street is the bottleneck of the system. It is comparable to the other paths. Therefore, one of the best traffic control policies could be an increase in the length of time the related traffic light is set to "green".
TABLE II: QUEUE LENGTH

\begin{tabular}{lllll}
\hline \hline Waiting time & Average & Half width & Min & Max \\
\hline Process 1. & 0.03761578 & 0.0007033024 & 0.0 & 5.0 \\
Process 2. & 1.5603 & 0.017104466 & 0.0 & 14.0 \\
Process 3. & 1.1946 & 0.011587921 & 0.0 & 14.0 \\
Process 4. & 11.7456 & 0.083718716 & 0.0 & 53.0 \\
\hline \hline
\end{tabular}

\section{3) Percentage of branching of vehicles}

Percentage of turning vehicles is described in Table III. As it can be seen, 679080 cars entered the system. Emam Street and Bazargani Street play the most important role in the actual traffic management.

TABLE III: VEHICLE BRANCHING

\begin{tabular}{lllll}
\hline \hline Street & Number in & $\%$ & Number out & $\%$ \\
\hline Bazargani & 288113 & 42.0 & 232987 & 34.0 \\
Bahonar & 66534 & 11.0 & 92337 & 15.0 \\
Helali & 51932 & .07 & 89703 & 13.0 \\
Emam & 272501 & 40.0 & 264070 & 38.0 \\
\hline \hline
\end{tabular}

\section{4) Scenario analysis}

In order to evaluate the performance of the traffic signal system and the resulting traffic flow, we have analyzed the system under different control policy. As shown in Table IV, a scenario represents a timing policy for green light code of each traffic signal. Scenarios are defined based on our extensive observation of the system under real operational policies.

As illustrated in Fig. 3, the system performs differently under each scenario. For example, if the timing policy number 9 is applied, the length of the queue in Emam Street reaches 24 cars in average, while it will be as low as 9 for Helali Street.

TABLE IV: OPERATIONAL SCENARIO SETTINGS

\begin{tabular}{lllll}
\hline \hline Scenario & Emam & Bazargani & Bahonar & Helali \\
\hline 1 & 36 & 44 & 13 & 9 \\
2 & 33 & 47 & 17 & 14 \\
3 & 29 & 35 & 9 & 24 \\
4 & 25 & 29 & 12 & 21 \\
5 & 16 & 22 & 10 & 17 \\
6 & 22 & 26 & 17 & 11 \\
7 & 11 & 29 & 21 & 14 \\
8 & 19 & 38 & 19 & 11 \\
9 & 24 & 41 & 11 & 9 \\
10 & 21 & 36 & 19 & 13 \\
\hline \hline
\end{tabular}

Fig. 3 shows that the system has a generally better performance if the timing policy 5 is applied. That is, the length of queue in the whole system reaches the lowest value. In this case, the system performs in an ideal condition.

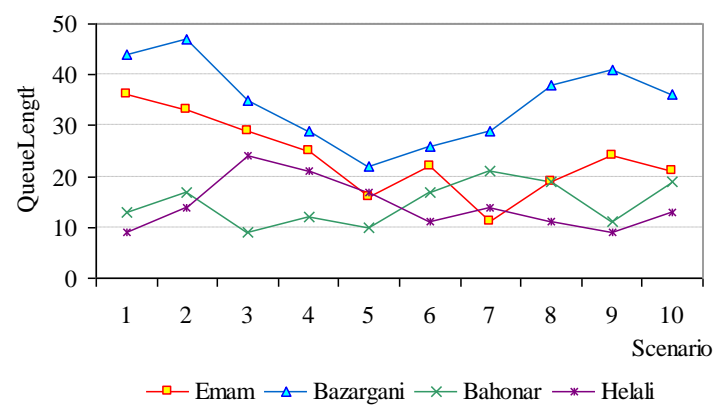

Fig. 3. Performance of the system. 


\section{SUMMARY}

Urban traffic control is one of the important problems in all countries. There have been lots of efforts and academic research to resolve the problem. Simulation is an approach which could be utilized in order to scientifically tackle the problem. Arena is a simulation tool widely being used for modeling and simulation of discrete event systems. However, it is not designed to be used for modeling urban traffic systems. In this paper, we presented a simulation modeling and analysis of an urban traffic signal control. A traffic signal system is described as a set of Arena modules. It has been shown that Arena could be used to model urban traffic if it is carefully utilized. The result of this research is used to improve the traffic flow of the intersection. The results show that the proposed modeling approach could be used as a basis for the analysis of different control policies such as the timing of green or red periods of traffic lights.

\section{REFERENCES}

[1] V. Tyagi, S. Darbha1, and K. R. Rajagopal, "A review of the mathematical models for traffic flow," International Journal of Advanced Eng Sci Appl Math, vol. 1, 2009, pp. 53-68.

[2] M. Chabrol, D. Sarramia, and N. Tchernev, "Urban traffic systems modelling methodology," International Journal of Production Economics: Control and Management of Productive Systems, vol. 99, 2006, pp. 156-176.

[3] M, Papageorgiou, C, Diakaki, V. Dinopoulou, A. Kotsialos, and Y. Wang, "Review of road traffic control strategies," in Proceedings of the IEEE, vol. 91, no 12, pp. 2043-2067.

[4] J. B. Sheu, "A composite traffic flow modeling approach for incident-responsive network traffic assignment," Physica A, vol. 367, 2006, pp. 461-478.

[5] W. Wen, and C. L. Yang, "A dynamic and automatic traffic light control system for solving the road congestion problem," WIT Transactions on the Built Environment (Urban Transport), vol. 89, 2006, pp. 307-316.

[6] Z. Liu, "A Survey of Intelligence Methods in Urban Traffic Signal Control," IJCSNS International Journal of Computer Science and Network Security, vol.7, no.7, July 2007.

[7] W. Wen, "A dynamic and automatic traffic light control expert system for solving the road congestion problem," Expert Systems with Applications, vol. 34, 2008, pp. 2370-2381.

[8] M. Dotoli, M. P. Fanti, and C. Meloni, "A signal timing plan formulation for urban traffic control," Control Engineering Practice, vol. 14, 2006, pp. 1297-1311.

[9] F. Boillot, S Midenet, and J. C. Pierrele'e, "The real-time urban traffic control system CRONOS: Algorithm and experiments," Transportation Research Part C, vol. 14, 2006, pp. 18-38.

[10] L. B. de Oliveira, and E. Camponogara, "Multi-agent model predictive control of signaling split in urban traffic networks," Transportation Research Part C, vol. 18, 2010, pp. 120 - 139.

[11] J. Wei, A. Wang, and N. Du, "Study of Self-Organizing Control of Traffic Signals in an Urban Network Based on Cellular Automata," IEEE transactions on vehicular technology, vol. 54, no. 2, march 2005.

[12] S. C. Wong, W. T. Wong, C. M. Leung, and C. O. Tong, "Group-based optimization of a time-dependent TRANSYT traffic model for area traffic control," Transportation Research part B, vol. 36, no. 4, pp. 291-312, 2002

[13] K. Sekiyama, J. Nakanishi, I. Takagawa,T. Higashi, and T. Fukuda, "Selforganizing control of urban traffic signal network," in IEEE Int. Conf. Systems, Man, Cybernetics, vol. 4, Oct. 7-10, 2001, pp. 2481-2486.

[14] B. L. Smith, M. J. Demetsky, and P. K. Durvasula, "A Multiobjective Optimization Model for Flexroute Transit Service Design," Journal of Public Transportation, vol. 6, no. 1, pp. 81-100, 2003.

[15] M. Chabrol, D. Sarramia, and N. Tchernev, "Generic modelling and simulation for Urban Traffic System," ESM2001, Prague, Czech Republic, 2001, pp. 976-980.

[16] J. S. Baras, W. S. Levine, and T. L. Lin, "Discrete-time point processes in urban traffic queue estimation," IEEE Trans. Autom. Control, vol. AC-24, pp. 12-27, 1979.
[17] A. Barisone, D. Giglio, R. Minciardi, and R. Poggi, "A macroscopic traffic model for real-time optimization of signalized urban areas," in Proceedings of IEEE conference on decision and control, USA, 2002, pp. 900-903.

[18] W. Hong and X. Q. Mu, "A cooperative fuzzy control method for traffic lights," Journal of System Simulation, vol. 13, no. 5, 2001, pp. 551553.

[19] E. Bingham, "Reinforcement learning in neurofuzzy traffic signal control," European Journal of Operation Research, vol. 131, 2002, pp. 232-241.

[20] M. Patel and N. Ranganathan, "IDUTC: An intelligent decision-making system for urban traffic-control applications," IEEE transactions on vehicular technology, vol. 50, May 2001, pp. 816-829.

[21] M. C. Choy and D. Srinivasan, "Hybrid cooperative agents with online reinforcement learning for traffic control," in Proc. 2002 IEEE Int Conf. Fuzzy Systems, vol. 2, May 2002, pp. 1015-1020.

[22] I. Porche and S. Lafortune, "Dynamic traffic control: Decentralized and coordinated methods," in Proc. IEEE Conf. Intelligent Transportation System, pp. 930-935, Nov. 9-12, 1997.

[23] P. Songchitruksa and E. N. Hard, "Queuing simulation of roadside survey station: Blocked traffic lane," Transportation Research Part A, vol. 42, 2008, pp. 857-873.

[24] X. Yang and W. Recker, "Simulation studies of information propagation in a self-organizing distributed traffic information system," Transportation Research Part C, vol. 13, 2005, pp. 370-390.

[25] J. K. Lee, Y. H. Lim, and S. D. Chi, "Hierarchical modeling and simulation environment for intelligent transportation systems," Simulation, vol. 80, no. 2, pp. 61-76, 2004

[26] Cicortas and N. Somosi, "Multi-agent system model for urban traffic simulation," in Proc. SACI'05: Second Romanian Hungarian Joint Symposium on Applied Computational Intelligence, 2005.

[27] S. T. Jeng, "Integrated freeway incident management, using data mining and expert systems," Master thesis, Singapore: National University of Singapore, 2003.

[28] E. Lopez-Neri, A. Ramirez-Trevino, and E. Lopez-Mellado, "Microscopic modeling framework for urban traffic systems simulation," in Proceedings of the 7th International Conference on System Simulation and Scientific Computing, Beijing, China, 2008.

[29] E. López-Neri, A. Ramírez-Treviño, and E. López-Mellado, “A modeling framework for urban traffic systems microscopic simulation," Simulation Modeling Practice and Theory, 2009, in press.

[30] D. Sadowski, V Bapat, and G Drake, "The ARENA Product Family: Enterprise Modeling Solutions," in Proceedings of Simulation Conference, Systems Modeling Corporation, 504 Beaver Street, Sewickley, Pennsylvania 15143, U.S.A, Winter 1998, pp. 205-212.

[31] D. A. Takus and D. M. Profozich, "ARENA Software Tutorial," in Proceedings of Simulation Conference, Systems Modeling Corporation, 504 Beaver Street, Sewickley, Pennsylvania 15143, U.S.A, Winter 1997, pp. 541-544.

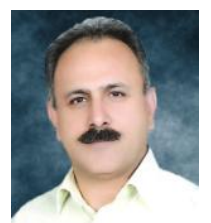

Khodakaram Salimifard was born in Borazjan, Iran, in 1962. He received his B.Sc. in industrial management from Shiraz University Iran in 1983. He received his M.Sc. in industrial management from Tarbiat Modares University, Iran in 1992. He received his Ph.D. in Management Science from Lancaster University UK in 2002. He was with Lancaster University management science department from 1999 to 2002 teaching operational research courses. Dr. Salimifard is an assistant professor of Management Science at the Industrial Management Department at Persian Gulf University, Bushehr Iran. Currently he is the head of the department. His main research interests include modeling and optimization of project scheduling and business processes using Petri nets and meta-heuristics (GA TS, SA, ACO). Also, he is interested in the applications of Coloured Petri nets $(\mathrm{CPN})$, discrete event simulation, and mathematical programming.

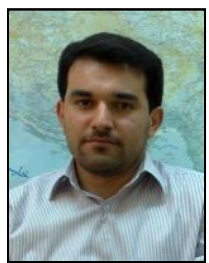

Mehdi Ansari holds a B.Sc. degree in industrial management from Amol University, Iran. He received his M.Sc. in operational research from Persian Gulf University, Bushehr Iran in 2011. His main research interests include modeling and simulation of urban traffic systems. Also, he is interested in the industrial applications of Coloured Petri nets, and discrete event simulation. 